Revista Temas Socio Jurídicos

Vol. 38 No 77 Julio - Diciembre de 2019

ISSN: 0120-8578

ISSN electrónico: 2590-8901

\title{
OS LIMITES DA PROTEÇÃO JURÍDICA E SEUS PONTOS DE VULNERABILIDADE DIANTE DAS NOVAS FORMAS DE TRABALHO
}

Cleiton Lixieski Sell ${ }^{1 *}$

Recibido: Abril 27 de 2019

Aprobado: Agosto 21 de 2019

\begin{abstract}
RESUMO:
O objetivo é abordar o direito ao trabalho na sociedade em rede. Dada essa linha orientadora, é sentida a interferência dos novos conceitos de trabalho, tanto no ambiente de trabalho, quanto na organização do trabalho, que tem sofrido mudanças consideráveis nos últimos anos. Para atingir os objetivos propostos, foi utilizado o método da abordagem dedutiva, baseado, teoricamente, no materialismo histórico; também o método de abordagem histórica, sintetizado pelo método de pesquisa de uma análise bibliográfica, utilizando como técnica a construção de autores que discutem o assunto. Foi realizada uma radiografia histórica do trabalhador, identificando uma evolução dos conceitos de trabalho diante das normas jurídicas que acompanharam essas mudanças na vida do trabalhador. Foi identificada uma precariedade jurídica, tanto do trabalhador quanto do empregado, uma vez que se relacionam o direito à liberdade, a privacidade e a intimidade, que se tornaram fundamentais nessa relação.
\end{abstract}

Palavras-chave: Trabalho humano; Relações trabalhistas; Informatização.

Citar este trabajo como: Lixieski, C. (2019). Os Limites da Proteção Jurídica e seus Pontos de Vulnerabilidade Diante das Novas Formas de Trabalho. En: Temas Socio-Jurídicos, 38(77), pp. 149-172. DOI: https://doi. org/10.29375/01208578.3594

1 * Máster en Derecho - Doctorando en Derecho en la UBU, España. Orcid: https://orcid. org/0000-0002-7324-1724. Correo electronico: cleitonls.direito@gmail.com 


\title{
LOS LÍMITES DE LA PROTECCIÓN JURÍDICA Y SU VULNERABILIDAD FRENTE A LAS NUEVAS FOR- MAS DE TRABAJO
}

\section{RESUMEN:}

El objetivo es abordar el derecho del trabajo en la sociedad en red. Ante este hilo conductor, las interferencias son sensiblemente sentidas en el ámbito laboral de los nuevos conceptos de trabajo, así como en la organización del trabajo que ha pasado en estos últimos años por transformaciones considerables. Para alcanzar los objetivos propuestos, se utilizó el método de enfoque deductivo, teniendo como teoría de base el materialismo histórico, y el método de enfoque histórico, que es sintetizado por el método de investigación de un análisis bibliográfico, utilizando como técnica, la construcción de autores que discuten el tema. Se realizó una radiografía histórica del trabajador, contemplando una evolución de los conceptos de trabajo ante las normas jurídicas que acompañaron esos cambios en la vida del trabajador. Se identificó una precarización jurídica tanto del lado del trabajador como del empleado, una vez que, están relacionados el derecho a la libertad, la privacidad y la intimidad, que pasó a ser fundamental en esa relación.

Palabras clave: Trabajo humano. Relaciones de trabajo. Informatización.

\section{LEGAL PROTECTION LIMITS AND ITS VULNERABI- LITY POINTS IN THE FACE OF THE NEW WAYS OF WORKING}

\begin{abstract}
:
The purpose is to address the labor law within the network society. Faced with this common topic, the new ways of working interfere in a sensitive way in the work environment, as well as in the work organization, which has gone through considerable changes in these last years. In order to achieve the intended goals, the deductive approach method was used, based on the historical materialism, and the historical approach method, which is synthesized by the research method of a bibliographic analysis, using as a technique, the development of authors that debate about the topic. A historical radiography of the employee was carried out, considering an evolution of labor concepts in connection with the legal standards
\end{abstract}


that have accompanied these changes throughout the employee's life. Legal instability was detected from both the employee and employer, once the rights of freedom, privacy and intimacy became connected; a process which became essential for this relationship.

Keywords: Human labor. Work relationships. Computerization.

\section{INTRODUÇÃo}

O meio ambiente e suas relações sofreram e ainda estão sofrendo fortes influências no que concerne o conceito de trabalho humano. Diante dessa dicotomia que historicamente é arraigada pela luta entre trabalhador e empregado, constrói-se uma abordagem que busca investigar de forma crítica o trabalho na sociedade em rede, na qual as relações trabalhistas e, por decorrência, a organização do trabalho, têm sido afetadas de maneira incisiva. Para tal pretensão, tornou-se imprescindível revisitar os aspectos da organização laboral, sendo caracterizada pela produção capitalista plasmada nas transformações tecnológicas, culminando na sua forma de organização laboral, que, por vezes, passa pela apropriação desigual da exploração das forças vulneráveis do trabalho.

Norteando essa temática, torna-se como pano de fundo o desenvolvimento de novas tecnologias, em especial ao que se refere ao campo da informática, em que se denotam os desenfreados avanços tecnológicos que repercutem em todos os setores sociais. Nesse sentido, para melhor compreensão do sistema vigente, e o consequente alcance das novas tecnologias, é imprescindível fazer uma viagem ao passado e comparar conceitos atuais com os presentes, no qual, à luz de sua época, estabelecem as relações com o meio ambiente. Nesse campo perverso onde habita o homem no meio ambiente, ocorre uma apropriação desigual dos frutos do progresso, pois as forças vulneráveis do trabalho, bem como a inserção subordinada em ambientes de trabalho, que são apresentadas como modernos, são, na realidade, uma reprodução das condições similares às existentes no pré-capitalismo.

Nessa nova visão trazida pela própria tecnologia, os conhecimentos tradicionais foram desvalorizados em decorrência do saber centralizado, em que até a violência do Estado é velada e, muitas vezes, mais violenta do que a das próprias populações. Nessa perspectiva, estamos diante de um período considerado internet das coisas, pois o próprio ser humano é controlado pela tecnologia, tornando-se refém dos sistemas peritos, como o elevador no qual depositamos toda a confiança de que não apresentará problemas. Quando reconhecermos esse esgotamento de antigas tradições, estaremos diante de um novo pensar coletivo, não só na visão antropocêntrica, que é dominada pelo homem, mas que também deverá ser pensada como um sistema de redes em que as funções passam a ser conectadas de múltiplas formas. 
Diferentemente de outros países da Europa, o Brasil é um país de modernização tardia. Esse fato torna-se mais claro, uma vez que, nos países mais desenvolvidos, grande parte das tecnologias que estão sendo empregadas no Brasil já está ultrapassada, tornando-se obsoletas. Entretanto, têm-se uma quantidade significativa de demandas de novas tecnologias, que passam por uma filtragem das mídias tradicionais, impossibilitando que os indivíduos enxerguem o problema do consumo exacerbado, vindo a recair em um ciclo, que é chamada por alguns autores como obsolescência programada.

Nesse cenário, começa-se a desenvolver uma nova estrutura denominada sociedade em rede. Essa denominação de redes constitui a nova morfologia social da sociedade, modificando de forma substancial a operacionalidade, bem como os resultados dos processos. É possível identificar uma realidade complexa por ambivalências, ou seja, existem vantagens e desvantagens, entre as quais, a extinção de postos de trabalho, como é o caso do varejo e do atacado, haja vista que se torna menos oneroso criar um site e vender seus produtos, vindo a atingir um público infinitamente superior, do que um vendedor abrir seu mercado para vender produtos. Desse modo, essa questão tem influência na própria cultura da sociedade, uma vez que, nem todos os indivíduos possuem as possibilidades de acesso e uso dessas tecnologias disponíveis.

Tendo como atuação as relações sociais espontâneas, o exercício da liberdade das pessoas é considerado livre e igual. Nesse aspecto, torna-se compreensível que o caminho que percorre a dicotomia entre público e privado não se sustenta e muito menos se torna justificável diante de um Estado que não dá conta de suas próprias funções e atribuições. Dessa forma, torna-se fundamental uma compreensão que envolve uma leitura própria, indo à busca de uma resposta adequada, tanto do lado do trabalhador quanto do empregador. A não compreensão dessa diferença resulta indistintamente a rejeição não unicamente do Estado, mas da própria sociedade, visto que a pluralidade apenas se mantém, ou se tolera, mas não pode ser reconhecida.

No âmbito metodológico, o desenvolvimento desse trabalho está ancorado no método dedutivo, que parte de fenômenos particulares, mantendo uma conexão descendente com os fatos observados no decorrer da investigação. Partindo desse método, a teoria de base se fundamenta no materialismo histórico, em que se utilizou como procedimento a análise bibliográfica de textos que compõem o tema em tela, que são as vulnerabilidades do trabalhador, bem como do empregador nas relações de trabalho.

Nesse caminho da análise sobre o trabalho humano, o texto propõe uma análise das relações no ambiente de trabalho, nas quais, por meio da informatização do trabalho, a proteção jurídica se tornou vulnerável, transformando-se em um marco histórico para os novos conceitos criados em virtude do avanço científico-tecnológico dos mecanismos de execução do 
trabalho. Nesse cenário, encontram-se o empregado e o empregador submetidos aos regramentos jurídicos como sua única forma de preservação dos direitos individuais, travando incansáveis embates que permeiam, sobretudo, o interesse econômico, que é a espinha dorsal desse sistema econômico que assola a população.

\section{O trabalho especificamente humano e suas relações na sociedade em rede}

Os elementos do trabalho podem ser comparados com uma peça de teatro, visto que cada indivíduo participa de uma parte da peça, em que, com a participação da coletividade, busca-se transmitir uma mensagem para o público. Essa identificação histórica se torna possível quando a tarefa de compilar essas informações é feita em várias camadas, nas quais o indivíduo se assemelha à diversidade de uma malha quando é lançada na água, em que os resultados identificam a especificidade em relação ao tamanho da espécie.

No aspecto paradigmático, o grande divisor de águas no processo de trabalho foi a $1^{\text {a }}$ Revolução Industrial, a partir de 1760 , em que ocorreu a mudança do processo até então conhecido e desenvolvido como manufatura para uma nova inserção de processos mais sofisticados, como máquinas e ferramentas mais eficientes, além de recursos naturais, como o excesso de utilização de madeira como forma de manter constante a temperatura de fontes de calor, tais como caldeiras e máquinas que utilizassem a queima da madeira como única matéria-prima fornecedora de calor.

A partir desse prequestionamento, o trabalho pode ser exercido de diversas formas, desde as formas mais simples, como pouco conhecimento intelectual e grande utilização de energia, até as de muito conhecimento intelectual específico e pouca utilização de esforço físico bruto. Diante dessas possibilidades em que se enquadra o trabalho humano, é possível identificar as mais distintas formas de manter suas relações. Esse fenômeno abordado é dado por uma construção artificial própria, uma vez que aquele que detém o poder explora aquele que não o possui.

O trabalho é pressuposto de qualquer outra atividade, sendo assim, está presente o tempo todo e em todo lugar no meio ambiente. $\mathrm{O}$ conceito de trabalho pode ser denominado como universal, pois ultrapassa as fronteiras territoriais, vindo a ser caracterizado também nos animais, como no caso dos aracnídeos, quando a aranha tece a teia onde captura o alimento para a sua sobrevivência. Nesse sentido, o trabalho é desenvolvido pelos seres humanos constantemente, seja durante uma caminhada ou após uma refeição quando os órgãos internos trabalham para digerir os nutrientes, seja quando fazemos uma leitura ou quando estamos descansando, já que é o momento em que o organismo fica relaxado e somente o cérebro e alguns órgãos internos essenciais trabalham. 
A palavra trabalho remete a várias ideias que, inicialmente, levam a acreditar que tratam unicamente de uma atividade ou tarefa. Nessa linha de raciocínio, encontramos o trabalho humano, que é desenvolvido diariamente pelo esforço físico ou intelectual do ser humano no meio ambiente. Desse modo, para que o trabalho humano possa ser desenvolvido é imprescindível que haja esforço físico (Marx, 2013). Contribuindo nessa linha, "o trabalho é, assim, uma simples mudança de forma do movimento, considerado sob seu aspecto quantitativo" (Engels, 1979, p. 67).

O conceito de trabalho, se for abordado na física, mostra-se obscuro em relação ao aspecto fundamental do movimento, como uma máquina de lavar roupas, que precisa de um agente que é a energia, podendo ser vapor (temperatura) ou elétrica, mas que se trata de trabalho, sendo, portanto, correspondente à própria quantidade que produziu. Dessa forma, o trabalho é antes de tudo um processo no qual participam o homem e a natureza, uma vez que propriedades físicas, químicas e biológicas são utilizadas para atuarem sobre outras fontes, as quais devem ser consideradas de forma abrangente.

Deve-se analisar o trabalho sob uma perspectiva que sempre existiu e continuará existindo, pois está inserido desde tarefas mais simples até as mais complexas. No entanto, não se pode negar a forma como esse trabalho é estabelecido na prática, pois, na medida em que existe um contrato de trabalho, são impostas regras para ambos os lados. O empregador está sujeito a diversas obrigações com o trabalhador, tais como: auxílio-transporte, plano de saúde, férias, décimo-terceiro salário, entre outros. Por outro lado, o trabalhador, quando assina um contrato de trabalho, vende automaticamente seu tempo de produção para uma atividade, assim como se sujeita à força de trabalho que produz.

Diante desse aspecto, o trabalho está presente em todas as atividades que o ser humano desenvolve, seja simples movimento físico ou intelectual, o qual estará intrínseco no trabalho. Sendo assim, "[...] o primeiro avanço significativo na divisão social do trabalho consiste em separar o trabalho industrial e comercial agrícola, o que conduz à distinção e oposição entre cidade e campo" (Marx, 2011b, p. 112). No meio ambiente, os animais também desenvolvem algum tipo de trabalho, mesmo não havendo a troca por dinheiro, contudo o realizam pela própria sobrevivência. Dessa forma, fica evidente a justificativa de que somente o trabalho leva à sobrevivência e perpetuação da espécie humana.

A importância do trabalho para a espécie humana é inquestionável, pois se de um lado ajuda no desenvolvimento profissional por meio do conhecimento e da experiência que adquire, por outro é no ambiente de trabalho que o homem está inserido a maior parte de sua vida. Os elementos fundamentais que fazem parte do processo de trabalho para Marx (2011a, p. 
212) são “[...] a atividade adequada a um fim, isto é, o próprio trabalho, a matéria a que se aplica o trabalho, o objeto de trabalho e os meios de trabalho, o instrumental de trabalho". Diante desses aspectos, vale lembrar que o ser humano tem conexão com o meio ambiente e que dele depende para sobreviver, independentemente de suas próprias forças naturais.

O produto do trabalho será sempre a sobrevivência, através da qual cada indivíduo está inserido em uma realidade diferente, onde se procura, por meio do trabalho, uma melhor condição socioeconômica do mundo, o qual está, cada vez mais capitalista e monopolizado pela classe dominante. Contudo, "[...] no processo do trabalho, o homem atua sobre a natureza a fim de adaptá-la às suas necessidades. O trabalho é atributo exclusivo do homem, necessidade natural eterna, condição fundamental da vida humana" (Nikitin, 1967, pp. 2-3).

O trabalho por sua natureza já é um componente que exemplifica o esforço físico e mental, independentemente da atividade que irá desempenhar. Dessa forma, os esforços que cada ser humano realiza são em virtude de comandos que têm como vertente o cérebro, que por sua vez, é responsável por todos os comandos do organismo vivo, estabelecendo relação direta com as consequências psíquicas que deixam marcas no trabalho. Além disso, o ser humano está mergulhado no trabalho desde sua existência, vindo a se adaptar às diversas especialidades ou habilidades com o passar do tempo.

Os empregadores partem do pressuposto de que todos os trabalhadores estão aptos ao mesmo cargo ou função, inexistindo uma análise sumária que, na maioria das vezes, não é realizada ao contratar o indivíduo, que é a capacidade que individualmente o ser humano tem em aprender e a desenvolver seu trabalho. Dessa forma, o trabalho, em sua essência, não se configura como uma destinação final em si mesmo, ou seja, não é com o trabalho que se prolongará a vida humana, mas sim como um objetivo de meio, uma vez que, será atingido o objetivo fim, que é a sobrevivência.

Tendo como referência os processos de trabalho do ser humano, Novais (2011, p. 97) identifica uma pergunta que assombra as classes trabalhadoras em relação à sua força de participação, a qual se emancipa ainda nos dias atuais, ou "o modelo japonês supera radicalmente no sentido de ir à raiz dos problemas - o tayolorismo-fordismo ou trata-se de uma mudança que não altera a natureza da relação de classes no capitalismo, [...]?”. Desse modo, as relações de trabalho tomam forma no meio ambiente a partir do momento em que se realiza uma relação de troca entre os indivíduos, na qual um é o executante e o outro é o empregador, que, a partir de determinadas atividades, podem ser remuneradas, como também não.

Entretanto, essa relação entre os seres humanos é caracterizada pelo trabalhador. Partindo-se dessa premissa, é importante destacar que os processos de trabalho sofreram transformações, que vão desde as legislações trabal- 
histas até a saúde do próprio trabalhador, indo de encontro à inserção das tecnologias nessa relação. Também, devemos mencionar que as condições do trabalho se tornam mais compactas e a única questão que é discutida é a produtividade do trabalhador em relação ao tempo de trabalho disponível.

O aspecto fundamental, na perspectiva das relações de trabalho, é a intensidade propriamente dita no exercício do trabalho em que, por sua vez, quando um empregador exige maior produção, naturalmente haverá maior intensidade. Dessa forma, "[...] a intensidade é, portanto, mais que esforço físico, pois envolve todas as capacidades do trabalhador, sejam as de seu corpo, a acuidade de sua mente, a afetividade despendida, ou os saberes adquiridos através do tempo ou transmitidos através do processo de socialização" (Rosso, 2007, p. 21).

É possível notar que até mesmo as formas de comércio mudaram suas configurações, haja vista que, há algum tempo, os objetos somente eram adquiridos na própria loja ou no comércio na cidade. Esse fato é justificado por Levy (2001), por que a venda desses serviços e mercadorias passaram a ser preferidos on line pelos consumidores quanto à oferta, sendo de acesso a todos esses produtos, vindo a prejudicar o comércio local, dado que, no ciberespaço, são oferecidas mais opções de compra. Na visão de uma sociedade em rede não se encontra mais preso no limite do Estado de uma rede dependente, mas de um plano muito mais aberto.

Quando se pergunta quem pode trabalhar, naturalmente a resposta parece óbvia, pois todos os seres humanos poderiam trabalhar. No entanto, o problema é em que tipo de trabalho, pois alguns são mais prejudiciais à saúde do próprio ser humano. Nessa perspectiva da exclusão do trabalho, deve ser observado que "[...] na sociedade atual, extremamente competitiva e tecnificada, que é a de multiplicar as barreiras seletivas, procurando justificá-las com uma capa de cientificidade, ao invés de procurar uma maior integração e de reduzir as condições patogênicas" (Berlinguer, 1988, p. 68).

No século 20, surge o livro branco, que versa sobre a ciência, a tecnologia e a informação. A partir desse momento histórico, começa a aparecer uma pluralidade de conceitos, tais como a sociedade da informação. Nesse ponto, sempre houve a informação, mas ela era vista sob um ponto estático, pois o que muda é uma percepção da dinamização dela se misturar na ideia de poder (Castells, 2013). Nesse sentido, a sociedade em rede é voltada para o viés econômico, apontando para um cenário em que o próprio sistema perito se torna uma invasão na convivência dos indivíduos, vindo a penetrar com o uso de aplicativos para seu trabalho.

Também nessa visão, quando se fala em globalização, recai invariavelmente no processo de trabalho, pois deixa de ser um sujeito de direitos, em que sua liberdade é discutida, assim como se torna evidente a prioridade que é seu limite no aspecto da saúde. 
De fato, a liberdade substancial diminui quando predomina a doença: porque o indivíduo fica em geral impedido de exercer uma ou mais de suas faculdades de decidir e agir; porque sua sorte passa a ser confiada a outros poderes, sobretudo quando o doente enquanto tal não é mais considerado cidadão portador de direitos; porque a doença, quando persistente, muitas vezes leva o indivíduo (e as nações) a um movimento para baixo, a um círculo vicioso de regressão, que traz o risco de se tornar irreversível (Berlinguer, 1999, p. 22).

Essa análise é um dos pontos cruciais que envolvem o bom desempenho do empregador durante sua atividade, portanto, não pode ser encarada como subproduto de comercialização nas relações de trabalho. Dessa forma, a liberdade do indivíduo é prejudicada, já que a resistência que o ser humano sofreu desde o período de colonização da América está mais presente e desenvolvido ainda, pois além de explorar o máximo trabalho do ser humano, este ainda está sujeito às devastadoras doenças que causam imunidade e levam o ser humano a desenvolver doenças cada vez mais precoces.

Diante dessas características do trabalho na sociedade em rede, é possível identificar que tomou as mais diversas formas em relação à sua configuração, vindo a estabelecer as relações de uma sociedade global. Nesse sentido, Castells (2013, p. 58) traz um conceito em que “[...] uma sociedade em rede é aquela cuja estrutura social é composta de redes ativadas por tecnologias digitais de comunicação e informação baseadas em microeletrônica”. Desse modo, a sociedade está, instantaneamente, conectada pelos meios tecnológicos, rompendo os aspectos de estrutura tradicional de vivência e convivência.

A verticalização crescente da tecnologia gera um mundo de exacerbações em que o equilíbrio já não é possível, e o que está em questão é: de que forma e se as novas tecnologias podem humanizar a espécie ou conduzi-la à barbárie. Diante desse aspecto, vivemos em uma época de ausência de vontade de projetos de futuro, com diminuição do horizonte das expectativas, e, consequentemente, o trabalho se encontra imerso na periferia do sistema capitalista, gravitando sobre novas formas de precariedade e dependência estrutural.

Paralelamente ao fato tecnológico, ocorre o fenômeno da globalização, que é uma aproximação das distâncias físicas do planeta. Para Giddens (1991), a globalização se trata da intensificação das relações econômicas e sociais em escala mundial, onde diferentes localidades se ligam de tal maneira que são modelados por eventos, tendo-se a ideia de local global. Em um sentido mais criterioso, Beck (1999) prescreve que, com a globalização, é algo que envolve várias dimensões, nas quais estão inseridas as dimensões política, ecológica, econômica, social e espacial.

Também nessa linha, enquanto ótica de observação, Santos (2002) trabalha 
a ideia de pluridimensionalidade, em que novos padrões de interdependência desafiam o Estado nacional, vindo a ter uma espécie de conexões dos fluxos financeiros entre organizações financeiras e empresas transnacionais. Ainda nesse sentido, é possível abordar que, na revolução da informação e da comunicação, como também na transformação do trabalho e das empresas, ocorrem na economia global, à crise das ideologias políticas bem como das crenças culturais, sendo que é onde se identificam os sinais de um momento decisivo na evolução da sociedade contemporânea.

\section{Vulnerabilidades que o empregado/empregador enfrenta no teletrabalho}

Na Constituição da República Federativa do Brasil de 1988 são tratados os princípios fundamentais do ser humano, desenvolvendo seus fundamentos, que contêm, além da soberania e da cidadania, a dignidade da pessoa humana, os valores sociais do trabalho e a livre iniciativa. Partindo desse pressuposto, procura-se "assegurar a todos a existência digna, conforme os ditames da justiça social, além da defesa do meio ambiente, mediante tratamento diferenciado conforme o impacto ambiental dos produtos e serviços, bem como de seus processos de elaboração e prestação", a fim de reduzir as desigualdades sociais e buscar o pleno emprego.

Na perspectiva do direito do trabalho, vale lembrar que, na Carta Magna, a questão da proteção dos direitos humanos fundamentais foi disposta no art. $5^{\circ}$, que ora incorpora ao ser humano em seu trabalho, sendo reguladas questões como: insalubridade, salário, tempo, exequibilidade etc. Diante desses mecanismos de proteção do ser humano, face à execução do trabalho, são analisados os aspectos que dizem respeito às legislações que amparam quaisquer trabalhadores diante das condições em que o trabalho é realizado. Contudo, é importante observar a pessoa humana, uma vez que é preciso que sejam aplicadas as regras estabelecidas pelas ordenanças jurídicas, a fim de não ferir princípios fundamentais e que lhe são tão caros.

Fazendo uma análise temporal no que tange a Primeira Guerra Mundial, até 1968, aparecem os movimentos operários os quais alcançaram, por meio da força política, o direito de viver, e que assim o conquistaram de forma primordial. Nesse momento, surgem as primeiras manifestações em relação à proteção da saúde do trabalhador, haja vista que o movimento tentava melhorias nas condições de trabalho e de saúde. Cabe ressaltar que, somente em 1916, é que as jornadas de trabalho foram reduzidas para oito horas diárias e as legislações que versavam sobre os acidentes de trabalho foram direcionadas para seguros privados; assim como os primeiros exames pré-admissionais e de controle do trabalhador que surgiram a partir de decretos de 1913 (Dejours, 1992). 
Fica clara na Carta Magna a questão da proteção do trabalhador em relação à sua execução, já que prevê no inciso XXII, do art. $6^{02}$, a redução dos riscos que devem ser observados nas suas relações, sendo eles de ordem sanitária, bem como os que remetem à questão da segurança. Com essa previsão Constitucional, ainda são previstos direitos como: duração do trabalho, remuneração, acidentes que porventura possam vir a ocorrer, não sendo isentas as peculiaridades de cada trabalho em legislações específicas, como as Consolidações das Leis do Trabalho (CLT).

Para os trabalhadores, são reconhecidos sistematicamente "[...], neste século, junto a outros fatores (como o reconhecimento dos direitos dos trabalhadores, das crianças e das mulheres) para um processo de valorização do corpo humano, que atingiu, ainda que em diferente medida, todas as classes e todos os indivíduos" (Berlinguer, 1993, p. 171). Nesse caminho de constantes evoluções, órgãos humanos se tornaram, inclusive, mercadoria para atender a alguma necessidade de sobrevivência. Também, nesse sentido, cada vez mais o ser humano procura aprimorar seu corpo, seja por meio de exercícios físicos ou de refeições balanceadas, buscando a beleza e a satisfação pessoal.

A luta do trabalhador diante dos direitos individuais é de longa data, pois desde a racionalização da América existiam explorações e vulnerabilidades sobre a vida íntima dos operários, uma vez que os serviços já eram, sem dúvidas, controlados pelas empresas. Nesta senda, também é importante destacar que, na medida em que o trabalhador se esforçava para obter um maior vencimento (salário), ou algum valor extra, o trabalhador entrava na luta contra o álcool, que é um dos agentes perigosos que destroem as forças de trabalho (Gramsci, 2008).

Dessa maneira, no que tange a prestação de serviços nas relações de trabalho, enquanto o detentor da propriedade é destinado à realização de sua função social junto ao desenvolvimento da atividade de negócio, para a qual foi constituída de maneira sustentável em relação ao meio ambiente, deve-se, acima de tudo, o devido respeito ao indivíduo que participa dessa relação no processo, sendo, consoante à figura do trabalhador. Também, devem ser percebidas nesta associação que as relações de trabalho sofrem constantes alterações e que cabe às partes envolvidas nesse processo se adaptarem.

O processo de reestruturação de uma produção perpassa pela lente dos trabalhadores, uma vez que, estando cada vez mais restritas, proporcionam o surgimento de um novo perfil de trabalhador, cada vez mais produtivo e mais consumista de produtos. Para tanto, "[...] diante das

2 Art. $6^{\circ}$ São direitos sociais a educação, a saúde, a alimentação, o trabalho, a moradia, o transporte, o lazer, a segurança, a previdência social, a proteção à maternidade e à infância, a assistência aos desamparados, na forma desta Constituição. [...].

XXII - redução dos riscos inerentes ao trabalho, por meio de normas de saúde, higiene e segurança. 
tendências, é possível afirmar que se trata de um período histórico de grande vulnerabilidade para os trabalhadores" (Chiavegato \& Navarro, 2013, p. 92). Além disso, historicamente, o trabalhador está mais vulnerável nesta relação do que o empregador ou contratante.

O trabalho propriamente dito propõe analisar o trabalhador sob a ótica de um sujeito que apresenta uma relação direta com seu empregador, na qual o carro chefe é o contrato de trabalho em que estão estabelecidas as cláusulas dessa relação. Nessa perspectiva, na qual o trabalho é o ponto crucial entre o homem e a sua sobrevivência, é preciso identificar os efeitos intrínsecos relacionados ao processo de trabalho que, por sua vez, identificam-se onerosamente ao homem, que se submete à opressão instantânea no meio ambiente em que opera.

Transversalmente, o ser humano passa a ser objeto exploratório de um sistema capitalista que, por sua vez, está permeado por uma sociedade alienada pela busca incessante de bens materiais, compondo um mar de lixo utilizado e, na sequência, depositado no meio ambiente. Nessa visão, é importante analisar o trabalho sob uma perspectiva que sempre existiu e que continuará existindo, já que não se pode negar a forma como se estabelece esse trabalho na prática, pois, na medida em que existe um contrato de trabalho, conforme abordado anteriormente, são impostas regras para ambos os lados, em que o empregador está sujeito a determinadas obrigações, assim como o trabalhador, tais como: auxílio-transporte, plano de saúde, férias, décimo-terceiro salário entre outros.

Outro ponto relevante, conforme já mencionado, é o local de trabalho, pois não apresenta mais uma variável definidora e independente do teorema organizacional. Diante desse viés, fatores como o controle e a sincronização do horário não se constituem um elemento diferenciador na escolha do trabalho (Silva, 2007). Conforme essa linha de raciocínio, Castells (2003) compara que a tecnologia da informação significa hoje tudo o que a eletricidade significou na Era Industrial, uma vez que sua capacidade de chegar a todos os lugares é tão rápida quanto à chegada da eletricidade.

Nesse sentido, é importante analisar os impactos que as novas tecnologias geram nas relações entre capital e trabalho, e a sua relação assimétrica em relação à saúde física e psíquica dos trabalhadores. Essas ditas novas tecnologias estão à disposição do ser humano, colocando uma reflexão sobre seu futuro como indivíduo e como espécie e, ao mesmo tempo, sobre o papel do direito e seu permanente dilema entre manter a ordem econômica e a política vigente. É clara a complexidade da ideia de mudar uma estrutura que já está constituída, no entanto, precisam ser observados aspectos fundamentais como a saúde.

A utilização intensiva das novas tecnologias e da comunicação (TICs) nas grandes empresas decorre da suma relevância que a inovação passou a ter 
nos quadros de intensa competitividade, sendo engendrado pela quebra dos monopólios estatais. Essa velocidade em que as informações chegam às pessoas é impressionante, uma vez que toda a comunicação acaba possuindo um lugar e espaço para discussão. No entanto, o fato de ter mais informação para apoderar nem sempre melhora o sistema, pois as empresas têm modelos que ainda estão se adaptando, como é o caso do teletrabalho, em que estão interligados por uma rede.

A inserção da tecnologia, que era vertical para uma maior organização, passou a ser horizontal, buscando novas perspectivas para inserção de novas oportunidades no mercado de trabalho. A existência de espaços públicos abertos e espaços privados fechados levam as informações as quais estão centralizadas na elite dos trabalhadores. Contrapondo esse ponto de vista, o simples fato de ter mais informação em seu poder, nem sempre melhora o processo, pois existem empresas que têm modelos que ainda estão se adaptando, como é o caso do teletrabalho, que passou a ser uma nova forma de trabalho.

Como uma forma de atenuar o desemprego, a Organização Internacional do Trabalho, por intermédio da convenção 177 e da recomendação 184, regulamentou o trabalho em domicílio. Essa convenção foi uma forma de considerar que a lei trabalhista se estenda aos trabalhadores em domicílio, pois essa relação implica contrato de trabalho que gera relação de emprego (Almeida, 2005). Diante dessa nova forma de execução do trabalho, surge a necessidade de uma redefinição do tempo e do espaço, tendo como resultados novos processos na organização e no desenvolvimento do trabalho em si, em que o empregado não precisa mais trabalhar na sede principal da empresa e sim no seu próprio domicílio, passando assim a ser chamado teletrabalho (Estrada, 2011, p. 60).

Fazendo uma análise do empregador bem como do empregado, ambos se sujeitam a essa nova modalidade de trabalho, em que aquele trabalho que era desenvolvido de forma tradicional passou a ser estabelecido das mais diversas formas. Assim, da mesma forma como a evolução da espécie humana ocorreu, as evoluções nas relações de trabalho ocorrem constantemente, uma vez que as profissões tomaram outros rumos, ou até mesmo deixaram de existir, como é o caso do motorneiro (condutor de bondes), que hoje passa a ser visto com uma nova configuração.

Nesse sentido, “[...] não devemos nos esquecer de que o teletrabalho consubstancia o ato de exercer atividades que podem ser realizadas em um domicílio ou local intermediário, visando à competitividade e flexibilidade nos negócios" (Mello, 1999, p. 9-10). Essa inovação do teletrabalho e suas consequências e efeitos no cotidiano dos empregados, são argumentados como, 
[...] vestir o termo, enfrentar o trânsito, chegar pontualmente, registrar ponto, almoçar fora de casa e se encontrar em meio a ruídos e conversas dos colegas. Essas ações rotineiras de quem trabalha em empresa já mudaram para mais de 10,6 milhões de brasileiros, que usufruem da liberdade de trabalhar no conforto da própria casa. Essa tendência norte-americana começa a ganhar a simpatia dos brasileiros com a promessa de redução de custos da corporação e aumento da produtividade dos funcionários (Estrada, 2011, p. 64).

Conforme demonstrado, com essa tendência em investir em trabalho realizado à distância, abrem situações que merecem discussões, como a questão da higiene do local de trabalho na residência ou no local de trabalho em que o trabalhador realiza suas atividades. Essas questões dão margem a uma série de questionamentos, em que também entra o papel do empregador, pois exige o cumprimento das atividades que são demandadas e, em contrapartida, o trabalhador fica vinculado às tarefas mesmo fora do horário de expediente.

Essas mudanças que ocorreram no transcorrer do tempo, afetam diretamente a execução desses trabalhos, pois na medida em que evolui seu aspecto executor, que é quando o operador ou executante adapta-se às novas formas, também são incorporados nesse processo de transformação das relações de trabalho os trabalhos técnicos que exigem do trabalhador um aperfeiçoamento intelectual, como também existem trabalhos que o esforço físico é maior. Desse modo, a internet passou a ser a base tecnológica para a forma organizacional da Era da Informação, tornando-se a principal rede distribuidora de informações, sendo um meio de comunicação que permite a comunicação de muitos com muitos.

Nesse âmbito das formas de teletrabalho, encontra-se o fronteiriço, que é aquele em que um teletrabalhador é residente em um determinado país e trabalha virtualmente em outro. Essa forma de trabalho está se expandindo de forma assustadora, pois existem formas de prestação de serviços, como a edição de livros em outras línguas, reduzindo os custos para sua produção e divulgação (Estrada, 2003). Essa nova modalidade de teletrabalho se torna um elemento na questão da movimentação geográfica, uma vez que há um significativo ganho no tempo em que se deslocariam, bem como outros custos adicionais, como hotéis, refeições, táxis etc.

Por outro lado, as empresas que lidam com a produção criativa são mais abertas e flexíveis na fiscalização de seus empregados que trabalham à distância, uma vez que “[...] a produtividade aumenta, pois não precisam se deslocar diariamente, economizam tempo, flexibilizam os horários, reduzem o nível de estresse e equilibram melhor o trabalho com a vida familiar e social. Além dos benefícios que isso traz para a empresa" (Estrada, 2011, p. 65). Também, como forma de minimizar os riscos da saúde 
mental dos trabalhadores, empresas adotam medidas interativas de alívio de estresse e depressão no ambiente de trabalho.

No entanto, um ponto negativo a ser destacado é a dificuldade das empresas em fiscalizar seus empregados à distância, pois diante da falta do requisito da subordinação e obediência, dá-se a relação entre empregado e empregador por meio da confiança. Tendo uma análise para um viés direcionado para oportunidades no mercado de trabalho, o teletrabalho oferece uma solução vantajosa em relação aos portadores de necessidades especiais, sobretudo na forma de deslocar-se para o local de trabalho, vindo a contribuir, em última análise, como forma de diminuir o desemprego (Santana, 2002).

Em outro viés, para conseguir vigiar a navegação do trabalhador, é exatamente a distração que a internet proporciona que obriga as empresas a utilizar o monitoramento da rede para se precaverem das ameaças advindas da internet, bem como para o controle por parte dos agentes que possuem acesso a informações restritas da empresa. Todavia, existem pontos negativos para ambos os lados da relação de trabalho, ou seja, tanto do empregado quanto do empregador, no que diz respeito ao teletrabalho, pois segundo Estrada (2011, p. 64), “[...] trabalhar em casa também tem seus pontos negativos, que começam na diminuição das relações interpessoais e podem terminar até mesmo em depressão".

Contribuindo na questão específica do teletrabalho, torna-se fundamental destacar que, é preciso ter mais regulamentação quanto à higiene, segurança e saúde no trabalho, uma vez que, com o trabalho em domicílio, são decorrentes os descasos com um programa de prevenção de riscos, bem como uma falta de fiscalização sobre a efetividade dos locais e dos equipamentos utilizados para desenvolver as atividades (Fincato, 2008). Contemplando esse tema, ressalta-se que "[...] vantagens e desvantagens são apontadas no uso do teletrabalho, sempre com alguma margem de variação, dependendo da ideologia que permeia o sujeito que as aponta. É certo, no entanto, que três serão as figuras atingidas: teletrabalhador, empresa e sociedade" (FINCATO, 2016, p. 2).

As mudanças provocadas pela era da velocidade da informação induzem ao pré-questionamento sobre a análise tradicional que faz o direito do trabalho das relações entre as mídias e ambiente do trabalho, e as novas formas de trabalho, visto que o processo de reestruturação global da economia dado pelo desenvolvimento científico-tecnológico está nos levando para as relações no mundo virtual. Dessa forma, "[...] na esfera dos julgamentos associados às metamorfoses do trabalho na contemporaneidade que o otimismo tecnológico aparece com mais contundência" (Braga, 2009, p. 61).

Outra questão que toma parte da análise do trabalhador é o registro dos acidentes de trabalho que ocorrem em todas as relações de trabalho. No Brasil, somente aqueles que estiverem sob o prisma das normas da CLT, 
Decreto-Lei 5.452, de $1^{\circ}$ de maio de 1942, com suas exceções, é que podem buscar algum tipo de direito diante do fato ocorrido. Nessa linha, o objetivo jurídico das legislações que visam estabelecer formas de proteção contra as vulnerabilidades do trabalhador se tornou uma preocupação cada vez maior, uma vez que os trabalhadores acabam adoecendo por sofrerem pressões na busca de um emprego e, quando estão empregados, lutam incessantemente todos os dias para poderem sobreviver ou sustentar a família.

As relações trabalhistas têm modificado significativamente a organização do trabalho nos últimos anos; trata-se de agentes poderosíssimos da comunicação, havendo um incessante processo tecnológico que passou a modificar hábitos, costumes e modo de vida, seja no trabalho, seja na vida profissional. Esse fato pode ser justificado, pois, "[...] estamos sempre conectados às tecnologias em rede, nas quais as distâncias diminuíram e isso autoriza a afirmar, sem receio, que a principal mudança observada na evolução humana é a velocidade da comunicação e a forma como ela se molda" (Grasseli, 2011, p. 24).

O trabalho é a manipulação do mundo natural e do artificial, mas o trabalho é também o próprio homem, pois este afeta o mundo pelo trabalho e, por ele, também é afetado. Nas circunstâncias massivas e de elevada velocidade, em que essa manipulação passou a ser efetuada, deslocando o trabalho de dimensão humana para se tornar mera condição de consumo. Nessa seara, Cheib (2010), fazendo uma análise do trabalhador, sintetiza que há um controle do empregador através da comunicação, na medida em que o trabalhador não consegue terminar o trabalho no seu local propriamente dito, recebe no seu endereço eletrônico, vindo a ferir direitos como o da privacidade.

Se analisarmos o tempo que o trabalhador está inserido no ambiente de trabalho, podemos identificar que é praticamente a maior parte do tempo de sua vida, pois trabalha profissionalmente em sua totalidade muito mais tempo do que se mantêm em momentos de lazer ou descanso. Essa força de trabalho está inerente ao ser humano e tomou proporções assustadoras, como a quantidade de horas diárias dedicadas a tal atividade. Ainda nesse viés, é inquestionável que o ser humano sofreu, e em determinados lugares ainda sofre, pelo abuso dos direitos humanos mínimos aceitáveis como um trabalhador, tanto na área rural quanto urbana.

Sendo assim, com a atual reconfiguração dos direitos humanos diante dos trabalhadores, alinhavados com o lento processo de adequação de leis favoráveis, que é comprovado historicamente, as quais se tornaram inevitáveis para as próximas gerações, visto que, cada vez se torna mais visível a exploração da força de trabalho humano, implicando como a única forma de gerar benefícios. Essas situações dificilmente são percebidas, e quando são identificadas, o trabalhador fica com receio de perder o emprego, já 
que, dependendo do caso, deverá ficar afastado, ficando omisso em revelar seu problema para o empregador.

Como aspecto a ser exemplificado, as relações de trabalho apresentam vulnerabilidades em todo tipo de trabalho, pois desde o deslocamento de sua residência até o local de trabalho exige-se certo risco. No entanto, essa questão foi pouco discutida, assim como ainda não foi comprovada através de estudos científicos sobre os efeitos psicológicos que o teletrabalhador porventura possa adquirir, em que só o tempo e os casos concretos deverão confirmar se existe alguma influência no desdobramento desses trabalhos realizados em domicílio ou através de um ambiente virtual.

Diante de um cenário de vulnerabilidade do trabalhador nas relações de trabalho, cria-se uma espécie de morfologia do trabalho, que passa a ser o trabalho desenvolvido em sua residência, onde o trabalhador une as atividades domésticas com o trabalho produtivo profissional, vindo a explorar ainda mais o trabalhador (Antunes \& Braga, 2009). Em se tratando de aspectos que o indivíduo apresenta na relação com o trabalho,

[...] deve-se levar em consideração três componentes da relação homem-organização do trabalho: a fadiga, que faz com que o aparelho mental perca sua versatilidade; o sistema frustração-agressividade reativa, que deixa sem saída uma parte da energia pulsional; a organização do trabalho, como correia de vontade de uma transmissão de vontade externa, que se opõe aos investimentos das pulsões e às sublimações (Dejours, 1992, p. 122).

As vulnerabilidades destacadas no ambiente de trabalho revelam um lado ainda desconhecido, pois se de uma forma são instituídas tecnologias cada vez mais atuais, da mesma forma as maneiras de execução vão sendo atualizadas. Consoante a esse entendimento, mesmo havendo a previsão legal do teletrabalhador que executa seu trabalho na empresa, alguns aspectos passam despercebidos, uma vez que, segundo o art. $6^{\circ}$ da CLT $^{3}$, estabelece que não haja diferença entre o trabalhador doméstico e o que desenvolve seu trabalho no local específico, na sua empresa (Menezes, Nedel \& Silva, 2015).

Nesse ponto, também são levantados alguns questionamentos, como de que forma será permitido ao empregado utilizar a rede social para divulgar os produtos para os clientes, pois parece que deverá haver então um meio termo entre o empregador e o empregado, pois, afinal de contas, se houver algum problema cuja responsabilidade pertença ao empregado, como poderá ser revertido um fato grave, pois, dependendo do material que for divulgado, poderá comprometer a clientela da empresa.

3 Art. 6o Não se distingue entre o trabalho realizado no estabelecimento do empregador, o executado no domicílio do empregado e o realizado a distância, desde que estejam caracterizados os pressupostos da relação de emprego. 
Cabe destacar que, no que se refere ao teletrabalho, mesmo se falando em trabalho realizado em domicílio, estão contemplados também outros trabalhos, que seguindo o ensinamento de Krieger (2013, p. 4), “[...] pode ser prestado em qualquer lugar, tanto dentro de um avião, como em um hotel, na praia ou em qualquer lugar, desde que tenha os equipamentos necessários para realizar a tarefa". O teletrabalho tem sido responsável por uma evolução no âmbito do trabalho, pois trouxe novas tendências com desdobramentos na área jurídica. Essa tendência mostra-se cada vez mais presente, pois são discutidas nos processos, situações inusitadas, em que muitas vezes, não existe uma norma capaz de atender as demandas, já que as próprias legislações devem atualizar-se constantemente, para evitar a defasagem jurídica em relação ao caso concreto.

Vale lembrar que os legisladores encontram dificuldades em relação à positivação do trabalho à distância, pois "[...] nas questões legislativas, a abordagem das matérias revela que o processo de elaboração jurídica é lento, considerando o acelerado e incessante desenvolvimento econômico-tecnológico" (Grasselli, 2010, p. 54). Nesse condão caminha o direito ao trabalho que, por sua vez, muitas das vezes é negado por esse aparato tecnológico, que "[...] atribui ao indivíduo à responsabilidade de obtê-lo a qualquer custo, bem como a culpa de não o conseguir, tornando-o cada vez mais vulnerável nesse mercado tecnológico" (Cardon, 2012, p. 46).

No ambiente de trabalho, já se instala a característica essencial do ser humano que é procurar se desenvolver, buscando inovar, reestabelecer e criar métodos em que acaba sendo inserido como ser pensante na espécie humana. Nesse sentido, Konder (2009, p. 132) faz uma crítica a esse aspecto, pois " [...] o trabalhador é considerado, então, uma espécie de robô deficiente, imperfeito, um autômato dotado de faculdade de produzir, mas incapacitado para ajustar completamente às exigências do processo racional da produção, quer dizer as exigências técnicas".

Nas relações de trabalho, como em qualquer profissão, os trabalhadores estão sujeitos aos acidentes de trabalho. Mas o que torna relevante essa preocupação é o fato de esses acidentes não serem informados da forma correta para quem é de direito, ou seja, são mascarados em âmbito interno, deixando muitas vezes, o trabalhador acidentado nas piores condições possíveis, isto é, "são reconhecidos e notificados internamente, mas localiza-se em um dos pontos que, [...] denomina os, [...] ângulos mortos do sistema" (Benjamin, 2003, p. 152).

Feita essa abordagem, tendo suporte no entendimento da doutrina, a forma tradicional que é a partir do direito, entre normas internacionais, com o mercado apresentando cada vez mais dispositivos para adesão do indivíduo, em que trabalha-se com a ideia de que aquele modelo está esgotado e que deve ser construído um novo espaço, no qual o indivíduo procura se adaptar a essa 
realidade. Essa rapidez do fato social e contrafluxo, é tão presente e constante que, muitas vezes, quando se está construindo um novo mecanismo ou tecnologia, já se possuem precedentes que devem ser regulados.

Nesse escopo que tem a figura do trabalhador diante das relações de trabalho é preciso que se tenha “[...] proteção especial ao homem enquanto ser humano e enquanto partícipe da relação jurídica contratual trabalhista" (Grasselli, 2010, p. 76). E um desses motivos se torna fundamental quando o trabalhador é sufocado pelo número de informações a todo tempo, e o trabalhador tendo que conviver além do período destinado à execução do trabalho propriamente dito, fica à mercê desses fantasmas que batem à porta através de sites que tentam vender seus produtos com diversas facilidades, causando inclusive um desconforto mental, na medida em que se torna rotineiro a divulgação de produtos.

Mesmo havendo uma considerável mudança nas condições de trabalho, “[...] muitos trabalhos continuam a ser executados em condições de grandes descomodidades, especialmente para os empregados na manutenção dos vagões ferroviários e para os trabalhadores das empresas navais" (Berlinguer, 1983, p. 106). Essa realidade mostra que o trabalhador está sujeito ao cansaço físico extremo, e muito pouco se fala em saúde mental e física desses trabalhadores, em um contexto em que a única regra, muitas vezes, é não ficar doente para não deixar de realizar seu trabalho.

No entanto, existem diversos doutrinadores que abordam a questão da legislação trabalhista no Brasil, sendo defasada ou omissa em pontos que cabem aos Tribunais Superiores ou de Justiça proferirem decisões de matéria controversa. Nesse sentido, alinha-se Tierra (2003, p. 82), quando prescreve que "[...] a legislação brasileira se encontra embasada nessa dicotomia entre fatores humanos e o ambiente de trabalho. Os riscos, os atos inseguros, o risco aceitável, os limites suportáveis pelo trabalhador, em geral, são caracterizados dentro das empresas".

É importante exemplificar que, quando se fala nas vulnerabilidades que a legislação possui, atingem todos os trabalhadores, que invariavelmente estão sujeitos às legislações trabalhistas, e que poucas são as estatísticas divulgadas que descrevem um desses aspectos, que são os acidentes de trabalho, pois os dados que se tornam públicos são somente os que têm sua carteira de trabalho registrada, que em outras palavras, traduz os trabalhadores formais, ficando excluídos os que não estão contemplados neste registro.

A organização do trabalho nas relações entre empregado e empregador sofreu alterações significativas em relação aos direitos trabalhistas e não se pode negar que essas mudanças interferem nos problemas complexos que surgem no âmbito do direito do trabalho e do direito previdenciário, com que este último possui estreita relação. Essa é uma tendência contemporânea é um período de tensões político-econômicas fortes, ocasio- 
nando reflexos diretos e indiretos para sociedade, que, possivelmente, terá que conviver com essa diversidade cada vez mais intensa.

\section{CONSIDERAÇÕES FINAIS}

Diante dessa análise substancial das relações de trabalho, podemos identificar que nos encontramos no presente já com uma perspectiva de futuro, na qual viver o presente e, com isso, uma vida cujas promessas, feitas por pais ou avós, de crescer e, posteriormente, trabalhar, seguindo sua função, não correspondem mais, pois agora temos uma nova compreensão do tempo e do espaço. Assim, com esses meios tecnológicos que batem à porta constantemente, caminhou-se em passos largos para uma virada normativa, na qual os indivíduos se tornaram sujeitos de direitos, que não está acompanhada de uma virada espacial, pois nem mesmo as cidades são planejadas para o tráfego de deficientes.

As vulnerabilidades dos indivíduos, no caso em questão, do trabalhador, tornam evidente a desigualdade que existe na relação de emprego, em que, na verdade, a tecnologia deveria ter, por finalidade, o papel de colaborar com a igualdade entre as partes no âmbito do direito do trabalho. Dessa forma, percebemos que as vulnerabilidades do trabalhador estão constituídas nas novas formas de execução do trabalho, que são o trabalho informacional, pois abrem um campo vasto para discussões sobre o processo estratégico-econômico do mercado, sendo ainda mascarado pela simplificação de gastos com trabalhadores, gerando uma forma de exploração do trabalho do homem pelo próprio homem.

Com essa pesquisa, identificou-se que os autores ora investigados possuem unanimidade em relação às vantagens e desvantagens que as novas modalidades de trabalho apresentam, podendo ser descritas de diversos pontos de vista, sendo uma forma de trabalho que possui uma nova classificação laboral, tanto para os empregadores quanto para o governo. Não se tem respostas prontas para serem analisadas a respeito dos efeitos dessas novas vulnerabilidades em que o trabalhador incorre. Precisa-se, inevitavelmente sair do campo puramente do direito, pois em última análise, trará respostas temporárias em virtude da diversidade das relações sociais, em que tanto o empregado quanto o empregador estiverem inseridos.

Torna-se relevante uma preocupação mais incisiva sobre o reconhecimento do trabalho realizado à distância, em que uma pergunta se torna fundamental nesse eixo, que é no caso o teletrabalho, pois - será que o judiciário terá condições de proteger essa modalidade? - uma vez que devem ser analisados os elementos da relação empregatícia, visto que foi demonstrado que, de certa forma, o trabalhador perdeu um pouco o aspecto de subordinação na relação entre o empregado e o empregador. 
Nessa perspectiva, existe um descompasso em relação ao tempo, pois parece que não se vive mais o presente, uma vez que as tecnologias tomaram as rédeas dos meios de comunicação do ser humano com o meio ambiente, que a partir de uma visão de uma sociedade em rede, não se está mais preso ao limite do Estado com o fundamento de uma rede dependente, mas de um plano muito mais aberto, voltado ao fundo econômico, em que os sistemas perfeitos, denominados sistemas ou plataformas, invadem a esfera das relações de trabalho, que podem abranger desde o operário de uma fábrica até o teletrabalho, em que são discutidas as fragilidades que essas novas formas de execução do trabalho trazem.

Feitas essas considerações, fica claro que as vulnerabilidades existem nas relações de trabalho, interferindo invariavelmente na saúde do trabalhador, que, em última análise, observa-se o aspecto superficial, ou nem é levada em consideração. Sendo assim, a proposta do texto caminha para respostas parciais sobre os efeitos dessas relações de trabalho, que estão inseridas na sociedade em rede, em que se permeiam as diversas esferas do direito.

\section{REFERÊNCIAS}

Almeida, L. (2005). Trabalho em domicílio: histórico e perspectivas: o teletrabalho. Revista dos Tribunais, 71(2) maio/ago, 63-93. Disponível em: https://hdl.handle.net/20.500.12178/3753

Antunes, R. \& Braga, R. (Orgs.) (2009). Infoproletariados. Degradação real do trabalho real. São Paulo: Boitempo.

Beck, U. (1999). O que é globalização? Equívocos do globalismo, respostas à globalização. São Paulo: Paz e Terra.

Benjamin, W. (2003). A história das histórias: análise e resultados. In J. M R. Mendes. $O$ verso e o anverso de uma história: o acidente e a morte no trabalho (pp. 135-201). Porto Alegre: PUCRS.

Berlinguer, G. (1983) A saúde nas fábricas. (H. A. Rothschild; J. R. de A. Bonfim, Trad.). São Paulo: CEBES-HUCITEC.

(1988). A doença. (V. Gawryszeski, Trad.) São Paulo: CEBES-HUCITEC.

(1993). Corpo humano: mercadoria ou valor? Estudos avançados, 7(19), Set/Dez, 167-192. Disponível em: http://www.scielo.br/scielo. php?script =sci_arttext\&pid=S01 03-40141993000300005

(1999). Globalização e saúde global. Estudos avançados, 13(35) Jan/Abr, 2137. Disponível em: http://www.scielo.br/scielo.php?script=sci arttext\&pid $=$ S0103-40141999000100003

Braga, R. (2009). Avingança de Braverman: otaylorismocomocontratempo. In: R. ANTUNES \& R. BRAGA (Orgs.). Infoproletariados: degradação real do trabalho virtual (pp. 59-88). São Paulo: Boitempo. 
Cardon, D. (2012). A democracia internet: Promessas e limites. Rio de Janeiro: Forense Universitária.

Castells, M. (2003). A Galáxia da Internet: reflexões sobre a Internet, os negócios e a sociedade. (M. L. D. A. Borges, trad.). Rio de Janeiro: Zahar.

(2013). O poder da comunicação. Lisboa: Fundação Caloust Gulbenkian.

Cheib, R. M. (2010). O Direito do Trabalho dos novos tempos: as novas tecnologias e garantias constitucionais e processuais, o direito à intimidade e de privacidade do empregado e do empregador. Rio de Janeiro: Lumen Juris.

Chiavegato, L. F. \& Navarro, V. L. (2013). A organização do trabalho em saúde em um contexto de precarização e avanço da ideologia generalista. In V. L. Navarro \& E. Â. Lourenço. (Orgs.) O avesso do trabalho III: saúde do trabalhador e questões contemporâneas (pp. 91106). São Paulo: Outras expressões.

Constituição da República Federativa do Brasil de 1998 Disponível em: http:// www.planalto.gov.br/ccivil 03/constituicao/constituicao.htm

Decreto-Lei n. 5.452, de $1^{\circ}$ de maio de 1943. Aprova as consolidações das Leis do Trabalho. In Diário Oficial da União. Brasília, DF, 08. Ago (1943). Disponível em: http://www.planalto.gov.br/ccivil 03/ decreto-lei/del5452.htm

Dejours, C. (1992). A Loucura do Trabalho. Estudo de Psicopatologia do Trabalho. (5. ed. ampl.). São Paulo: Cortez Oboré.

Engels, F. (1979). Anti-Dühring. (3. ed.) Rio de Janeiro: Paz e Terra.

Estrada, M. (2003). O teletrabalho transfronteiriço no Direito Brasileiro. Revista de Derecho Informático. (055) fev. Disponível em: https:// www.conjur.com.br/2002-dez-30/teletrabalho transfronteirico direito brasileiro

(2011). Breve panorama do teletrabalho no Brasil, nos Tribunais brasileiros e no Exterior. Congreso Iberoamericano de Derecho e Informática. Monterrey, Nuevo León, México, XIV. Disponível em: http://ru.juridicas.unam.mx/xmlui/handle/12345 6789/31527

Fincato, D. (2003). Teletrabalho: uma análise juslaboral. Revista de Direito Social, 3(11) jul/set, 29-45. Disponível em: https://bdjur.tjdft.jus. br/xmlui/handle/123456789/138 38? show =full

(2008). Acidente de trabalho e teletrabalho: novos desafios à dignidade do trabalhador. Revista Direitos Fundamentais e Justiça, (4) jul/ago, 1-13. Disponível em: https://www.passeidireto.com/arquivo/26361886/ acidente-do-trabalho-e-tele trabalho-novos-desafios-a-dignidadedo-trabalhador/10 
Giddens, A. (1991). As consequências da modernidade. (Raul Fiker, Trad.). São Paulo: Editora UNESP.

Gramsci, A. (2008). Americanismo e Fordismo. (4. ed.) São Paulo: Hedra.

Grasselli, O. (2010). O direito derivado da tecnologia: circunstâncias coletivas e individuais no Direito do Trabalho. São Paulo: LTr.

(2011). Internet, correio eletrônico e intimidade do trabalhador. São Paulo: Letras.

Konder, L. (2009). Marxismo e Alienação. Contribuiçãa para um estudo do conceito marxista de alienação. São Paulo: Expressão popular.

Krieger, M. A. (2013). Teletrabalho: ideias basilares. Páginas de direito. Setembro. Disponível em: https://www.paginasdedireito.com.br/ index.php/artigos/167-artigos-jan-2013/4748-teletrabalho-ideias$\underline{\text { basilares }}$

Lei n. 8.078, de 11 de setembro de 1990. Dispõe sobre a proteção do consumidor e dá outras providências. In Diário Oficial da União. Brasília, DF, 12. Set. 1990. Disponível em: http://www.planalto. gov.br/ccivil 03/leis/L8078.htm

Lévy P. (2001). A conexão planetária: o mercado, o ciberespaço, a consciência. (M. L. Homem \& R. Entler, trad.). São Paulo: 34.

Marx, K. (2011a). O capital: crítica da economia política. Livro 1: o processo de produção do capital. (28. ed., Vol. 1) (R. Sant'Anna, trad.). Rio de Janeiro: Civilização brasileira.

(2011b). Formações econômicas pré-capitalistas. (7. ed.) (J. Maia, trad.) São Paulo: Paz e Terra.

(2013). O capital: crítica da economia política. Livro 1: o processo de produção do capital. (R. Enderle, trad.). São Paulo: Boitempo.

Mello, Á. (1999). Teletrabalho (Telework): O Trabalho em Qualquer Lugar e a Qualquer Hora... Rio de Janeiro: Qualitymark.

Menezes, C., Nedel, N. \& Silva, R. (2015). O Dumping social como um novo desafio que emerge do teletrabalho: Delineamento teórico e possíveis alternativas de enfrentamento. Prim@ Facie, 14 (27), 1-29. Disponível em: periodicos.ufpb.br/index.php/primafacie/ article/download/25901/15423

Nikitin, P. (1967). Fundamentos de economia política. (À. Veiga Fo, Trad.). Rio de Janeiro: Civilização brasileira.

Novaes, H. T. (2011). O retorno do caracol a sua concha: alienação e desalienação em associações de trabalhadores. São Paulo: Expressão Popular. 
Rosso, S. D. (2007). Mais trabalho! A intensificação do labor na sociedade contemporânea. São Paulo: Boitempo.

Santana, S. \& Rocha, N. P. (2002). Teletrabalho: que oportunidade de trabalho para o cidadão incapacitado?. Análise Psicológica, 20(3), 419-431). Disponível em: http://www.scielo.mec.pt/scielo. php? script $=$ sci abstract $\&$ pid $=S 0870-82312002000300016 \& \operatorname{lng}=$ pt\&nrm =iso

Santos, B. (Org.) (2002). A globalização e as ciências sociais. São Paulo: Cortez.

Silva, A. F. da (2007). O teletrabalho, uma forma de transformação do emprego. Scripta Nova. 69 (61). Disponível em: http://www. ub.edu/geocrit/sn-69-61.htm

Tierra, P. (2003). A construção de uma dispersa demanda: o acidente de trabalho. In J. M. R. MENDES. O verso e o anverso de uma história: o acidente e a morte no trabalho (pp. 94-134). Porto Alegre: PUCRS. 